\title{
The effects of the histone deacetylase inhibitor 4-phenylbutyrate on gap junction conductance and permeability
}

\author{
Joshua Kaufman, Chris Gordon, Roberto Bergamaschi, Hong Z. Wang, Ira S. Cohen, Virginijus Valiunas and \\ Peter R. Brink*
}

Department of Physiology and Biophysics, Stony Brook University, Stony Brook, NY, USA

\section{Edited by:}

Stefan Dhein, Universitätsklinik Leipzig Herzzentrum Leipzig GmbH, Germany

\section{Reviewed by:}

Stefan Dhein, Universitätsklinik Leipzig Herzzentrum Leipzig GmbH, Germany

Klaus Willecke, University of Bonn, Germany

\section{*Correspondence:}

Peter R. Brink, Department of Physiology and Biophysics, Stony Brook University, Stony Brook, NY 11794-8661, USA

e-mail:peter.brink@stonybrook.edu
Longitudinal resistance is a key factor in determining cardiac action potential propagation. Action potential conduction velocity has been shown to be proportional to the square root of longitudinal resistance. A major determinant of longitudinal resistance in myocardium is the gap junction channel, comprised connexin proteins. Within the ventricular myocardium connexin43 (Cx43) is the dominantly expressed connexin. Reduced numbers of gap junction channels will result in an increase in longitudinal resistance creating the possibility of slowed conduction velocity while increased numbers of channels would potentially result in an increase in conduction velocity. We sought to determine if inhibition of histone deacetylase (HDAC) by 4-phenylbutyrate (4-PB), a known inhibitor of HDAC resulted in an increase in junctional conductance and permeability, which is not the result of changes in single channel unitary conductance. These experiments were performed using HEK-293 cells and HeLa cells stably transfected with $\mathrm{C} \times 43$. Following treatment with increasing concentrations of 4-PB up-regulation of $\mathrm{C} \times 43$ was observed via Western blot analysis. Junctional $\left(g_{\mathrm{j}}\right)$ conductance and unitary single channel conductance were measured via whole-cell patch clamp. In addition intercellular transfer of lucifer yellow (LY) was determined by fluorescence microscopy. The data in this study indicate that 4-PB is able to enhance functional $\mathrm{C} \times 43$ gap junction coupling as indicated by LY dye transfer and multichannel and single channel data along with Western blot analysis. As a corollary, pharmacological agents such as 4-PB have the potential, by increasing intercellular coupling, to reduce the effect of ischemia. It remains to be seen whether drugs like 4-PB will be effective in preventing cardiac maladies.

Keywords: connexin43, 4-phenylbutyrate, gap junction, conductance, permeability

\section{INTRODUCTION}

In multicellular organisms, the direct communication between adjacent cells is mediated via protein structures known as gap junctions (Sohl and Willecke, 2004). Connexins belong to a family of integral membrane proteins that form the underlying structure of gap junctions (Pointis, 2006). Various compounds including metabolites, ions, and fluorescent dyes can be exchanged from cell to cell via passive diffusion through these protein channels. Gap junctions consist of two smaller hemichannels called connexons, which are each composed of six smaller subunits called connexins. These protein channels are responsible for coordinating cellular activity in most biological systems including the myocardium, brain, and vascular endothelium.

The present study is focused on the role of connexin 43 (Cx43) found predominantly in ventricular myocardium. In the myocardium, gap junctions create an electrical conduit between adjacent cells that is vital to normal cardiac function. The result is a synchronized propagating action potential and subsequent muscle contraction that starts in the sinoatrial (SA) node and ends within the cells of the ventricular myocardium. The conduction velocity of the cardiac action potential is linked to the longitudinal resistance arising from cytoplasm and gap junctional membranes (Rudy, 2001; Donahue and Laurita, 2011) where conduction velocity, $\theta$, is inversely proportional to the square root of longitudinal resistance, $R_{\mathrm{i}}$ or $\left(\theta \propto 1 / \sqrt{R_{i}} ;\right.$ Hodgkin and Huxley, 1952).

Under pathological conditions such as cardiac ischemia rapid changes in ionic homeostasis often cause irreparable cellular damage that can affect gap junction distribution within myocytes (Saffitz et al., 2007). Ischemia also induced uncoupling in myocytes and has been linked to the induction of reentrant currents seen during ventricular tachycardia (VT; Xing et al., 2003).

4-Phenylbutyrate (4-PB) belongs to a group of agents known as histone deacetylase (HDAC) inhibitors, and is currently used as a promising anti-cancer drug (Khan et al., 2007). In previous studies, the drug 4-PB has been reported to increase $\mathrm{Cx} 43$ expression (Asklund etal., 2004; Khan etal., 2007). HDACs are able to induce histone hyper-acetylation, altered chromatin structure, and modulations in gene expression that allow for increased mRNA transcription. By causing DNA to lose its affinity to histone proteins, exposure of portions of DNA allow for increased mRNA transcription that codes for increased $\mathrm{Cx} 43$ translation. 
The aim of this study was to investigate the role of 4-PB with regards to its ability to induce increases in junctional conductance and correlate it with up-regulation of Cx43. It was hypothesized that those cells that were exposed to 4-PB would express increased levels of $\mathrm{Cx} 43$, as previously reported (Asklund et al., 2004; Khan et al., 2007) and result in an increased number of gap junction channels. Following treatment with increasing concentrations of 4-PB, up-regulation of $\mathrm{Cx} 43$ was observed via Western blot analysis consistent with previous studies (Asklund et al., 2004; Khan et al., 2007). Junctional conductance $\left(g_{j}\right)$ and intercellular transfer of lucifer yellow (LY) were measured via the whole cell patch clamp and by fluorescence microscopy. Demonstration that 4-PB can increase gap junction conductance and reduce longitudinal resistance allows for its potential use as an agent to reduce life-threatening conduction abnormalities, including reentrant ventricular arrhythmias.

\section{MATERIALS AND METHODS CELLS AND CULTURE CONDITIONS}

Experiments were performed on HeLa cells stably transfected with mCx43 or HEK-293 cells that were endogenously expressing Cx43. Production and characterization of these cells, culture conditions, and staining methods for identification of specific cells have been described previously (Valiunas et al., 2000, 2001, 2004; Gemel et al., 2004). Experimental groups of cells were cultured with a medium containing $5 \mathrm{mM}$ of 4 -PB. Both the control and experimental groups of cells were plated onto glass coverslips 1-3 days prior to experimentation and were stored in a $\mathrm{CO}_{2}$ incubator $\left(5 \% \mathrm{CO}_{2}\right.$, $95 \%$ ambient air at $37^{\circ} \mathrm{C}$ ) Electrophysiological measurements and dye flux studies were carried out on cell pairs and linear arrays triplets, respectively.

\section{ELECTROPHYSIOLOGICAL MEASUREMENTS}

These experiments were preformed on HEK-293 and HeLa Cx43 cell pairs. A dual voltage clamp method and whole cell recording were used to control the membrane potential of both cells and to measure currents. For electrical recordings, glass coverslips with adherent cells were transferred to an experimental chamber mounted on the stage of an inverted microscope (Olympus IMT-2) equipped with epi-fluorescence imaging. The chamber was perfused at room temperature (RT; $22^{\circ} \mathrm{C}$ ) with bath solution containing (in $\mathrm{mM}$ ) $\mathrm{NaCl}, 150 ; \mathrm{KCl}, 10 ; \mathrm{CaCl}_{2}, 2$; HEPES, 5 ( $\mathrm{pH} 7.4$ ); glucose, 5; $2 \mathrm{mM} \mathrm{CsCl}$ and $\mathrm{BaCl}_{2}$ were added. The patch pipettes were filled with solution containing (in $\mathrm{mM}$ ) $\mathrm{K}^{+}$aspartate $^{-}, 120 ; \mathrm{NaCl}, 10$; MgATP, 3; HEPES, 5 ( $\mathrm{pH} 7.2)$; EGTA, 10 ( $p \mathrm{Ca} \sim 8$ ); filtered through $0.22-\mu \mathrm{m}$ pores. Patch pipettes were pulled from glass capillaries (code GC150F-10; Harvard Apparatus) with a horizontal puller (Sutter Instruments).

\section{DYE FLUX STUDIES}

Experiments were performed on $\mathrm{HeLa} \mathrm{Cx} 43$ cell triplets that were linearly coupled, using the direct dye injection technique. LY (Molecular Probes) was dissolved in the pipette solution to reach a concentration of $2 \mathrm{mmol} / \mathrm{L}$. The donor cell was attached to a patch pipette connected to a micromanipulator (Narishige International), and an amplifier (Axopatch 200B) so that the membrane potential could be observed to help obtain the whole cell patch. The use of the whole cell patch clamp was used to ensure delivery of dye intracellularly without leakage into the bathing solution. Fluorescent dye cell-to-cell spread was monitored using the digital charge-coupled diode (CCD) camera PixelFly (12-bit; The Cooke). LY concentration is directly proportional to fluorescence intensity. A picture of the cell triplet's fluorescence was taken every $60 \mathrm{~s}$ over a period of $10 \mathrm{~min}$ (CamWare v2.10). Fluorescence intensity of each cell was measured and recorded every minute. The background intensity was subtracted from the respective images.

\section{WESTERN BLOT}

HEK-293 cells were collected from $35 \mathrm{~mm}$ plates by scraping. Cell suspensions were centrifuged at $14000 \mathrm{rpm}$ at RT for $5 \mathrm{~min}$ (calculated $g=13148$ ), supernatants were removed, and the pellets were re-suspended in cold $1 \times$ phosphate-buffered saline (PBS). The pellets were centrifuged, supernatants removed, pellets then re-suspended in cold radio-immnuoprecipitation assay (RIPA) buffer (R0278, Sigma), protease inhibitor cocktail (AEBSF, aprotinin, bestatin hydrochloride, E-64, EDTA, leupeptin; P2714, Sigma), sodium orthovanadate (S-6508, Sigma), and PMSF (P7626, Sigma). Samples were then centrifuged at $4^{\circ} \mathrm{C}, 14000 \mathrm{rpm}$ ( $g=13148$ ) for $10 \mathrm{~min}$, supernatants were transferred to prechilled microtubes. Protein concentration of each sample was determined by the Bradford assay. Volumes containing $30 \mu \mathrm{g}$ of total protein of each lysate were mixed with equal volumes of Laemmli sample buffer (161-0737, Bio-Rad) containing $\beta$ mercaptoethanol and boiled for $5 \mathrm{~min}$ at $95^{\circ} \mathrm{C}$. All samples were centrifuged for $1 \mathrm{~min}$ at $14000 \mathrm{rpm}(g=13148)$ at RT before being loaded on a SDS-polacrylamide gel (4\% stacking gel, 10\% separating gel). Prestained Protein Ladder (SM0671, Fermentas) or MagicMark XP Protein Standard (LC5602, Invitrogen) was loaded along with the samples. After separation by electrophoresis, proteins were transferred to Immobilon-P membrane (Millipore) by electrophoresis in tris-glycine/methanol buffer. Non-specific antibody binding was blocked for $1 \mathrm{~h}$ at RT in 5\% Blotting Grade Blocker non-fat dry milk (Bio-Rad) dissolved in $1 \times$ TBST (mixture of Tris-buffered saline and Tween 20). A 43-kDa protein was probed for by incubating the membrane with the Anti-Connexin 43 antibody (C 6219, Sigma) at 1:8000 in 1\% milk for $1 \mathrm{~h}$ at RT. After washing the membrane well the membrane was incubated with goat anti-rabbit IgG-HRP (sc-2004, Santa Cruz) at $1: 10000$ in $1 \%$ milk. After washing the secondary antibody was detected using SuperSignal West Femto Maximum Sensitivity Substrate (34095, Pierce) and images obtained by exposing the membrane to HyBlot CL Autoradiography Film (E3012, Denville Scientific).

As a loading control for normalization a $55 \mathrm{kDa}$ protein was probed for by incubating the membrane for $1 \mathrm{~h}$ at RT with Anti- $\alpha$ Tubulin (sc-8035) at 1:1000 in 1\% milk. After washing the membrane well with $1 \times$ TBST the membrane was incubated for $1 \mathrm{~h}$ at RT with goat anti-mouse IgG-HRP (sc-2005) at $1: 10000$ in $1 \%$ milk. After washing the membrane well with $1 \times$ TBST the secondary antibody was detected using SuperSignal West Femto Maximum Sensitivity Substrate (34095, Pierce) and images obtained by exposing the membrane to HyBlot CL 
Autoradiography Film. ImageJ software (NIH) was used for analysis and quantification of Western blot data.

\section{SIGNAL RECORDING AND ANALYSIS}

Voltage and current signals were recorded using patch clamp amplifiers (Axopatch 200b). The current signals were digitized with a 16-bit A/D-converter (Digidata 1322A; Molecular Devices) and stored with a personal computer. Data acquisition and analysis were preformed with pClamp9 software (Molecular Devices). Curve fitting and statistical analyses were performed using SigmaPlot and SigmaStat, respectively (Jandel Scientific). The Mann-Whitney rank sum test was used for all cases unless otherwise noted, $p<0.05$ was considered to indicate significant changes. The results are presented as means \pm SEM.

\section{RESULTS}

\section{LY DYE TRANSFER}

We compared the LY dye spread in control cells and in cells exposed to $4-\mathrm{PB}$ for $48 \mathrm{~h}$. All trials were performed using HeLa Cx43 cell triplets. The amount of LY transfer was determined over time by epi-fluorescence microscopy. One such experiment is depicted in Figure 1A. As time elapses, the concentration of LY within a given cell increases due to diffusion of LY from electrode to the first source cell then to adjacent cell through gap junction channels. In this case, three time points are shown

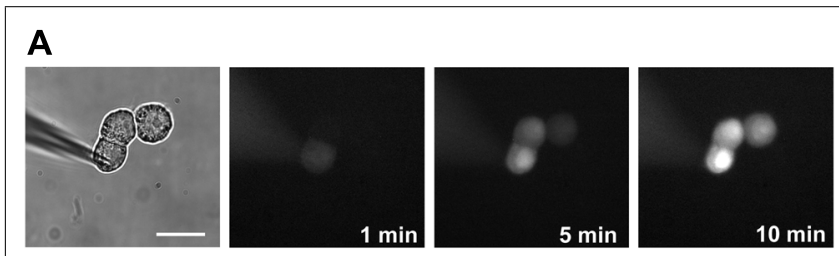

B

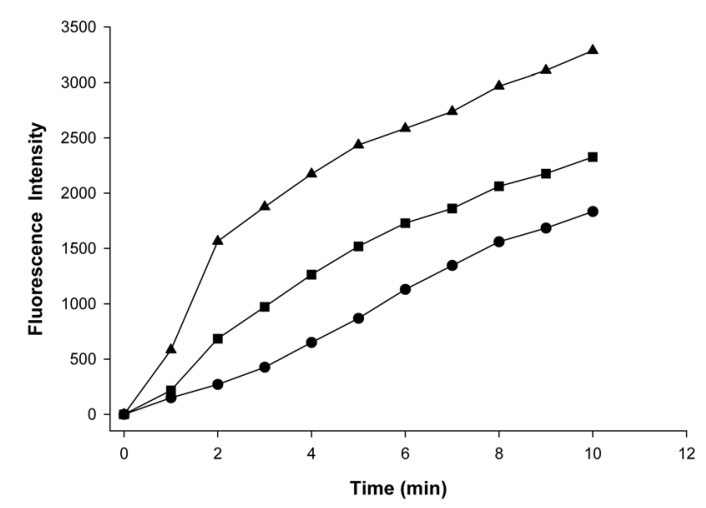

FIGURE 1 | (A) A pipette containing $2 \mathrm{mmol} / \mathrm{L}$ LY was attached to the cell furthest to the left in whole cell configuration. Epi-fluorescent micrographs were taken at 1, 5, and 10 min after dye injection into the first cell and showed a progressive fluorescence intensity increase in the two adjacent recipient cells. Scale bar: $20 \mu \mathrm{m}$. (B) Quantification of cell-to-cell spread of LY. Fluorescence intensity plots versus time for the $5 \mathrm{mM}$ 4-PB HeLa Cx43 cell trial shown in (A): first (injected) cell $(\mathbf{\Lambda})$, second cell ( $\mathbf{\square})$, and third cell (•).
(1, 5, and $10 \mathrm{~min})$ after dye injection. Once a linearly coupled cell triplet was identified, the patch pipette containing LY was attached to the donor or source cell in the whole cell mode. Fluorescence intensity was subsequently determined at 1-min time intervals for each experiment in all cells of the triplet. Figure 1B shows fluorescence intensity data for the experiment seen in Figure 1A.

Figures 2A,B summarize the fluorescence intensity data obtained from six experiments in $\mathrm{HeLa} \mathrm{Cx} 43$ control cells and four experiments with $5 \mathrm{mM} 4$-PB exposed cells, respectively. This data shows the relative fluorescent intensities for the first (source) cell $(\boldsymbol{\Delta})$, second cell $(\boldsymbol{\bullet})$, and third cell $(\bullet)$. The maximum (steady state) intensity attained in the source cell represents the equivalent of the concentration in the pipette. Fluorescence intensity in each cell increased with time in both the control and $5 \mathrm{mM} 4-\mathrm{PB}$ exposed cells. The increases in fluorescence intensity were normalized in both groups of experiments. There was a marked difference, between control and $5 \mathrm{mM} 4$-PB cells, in dye transfer to the third
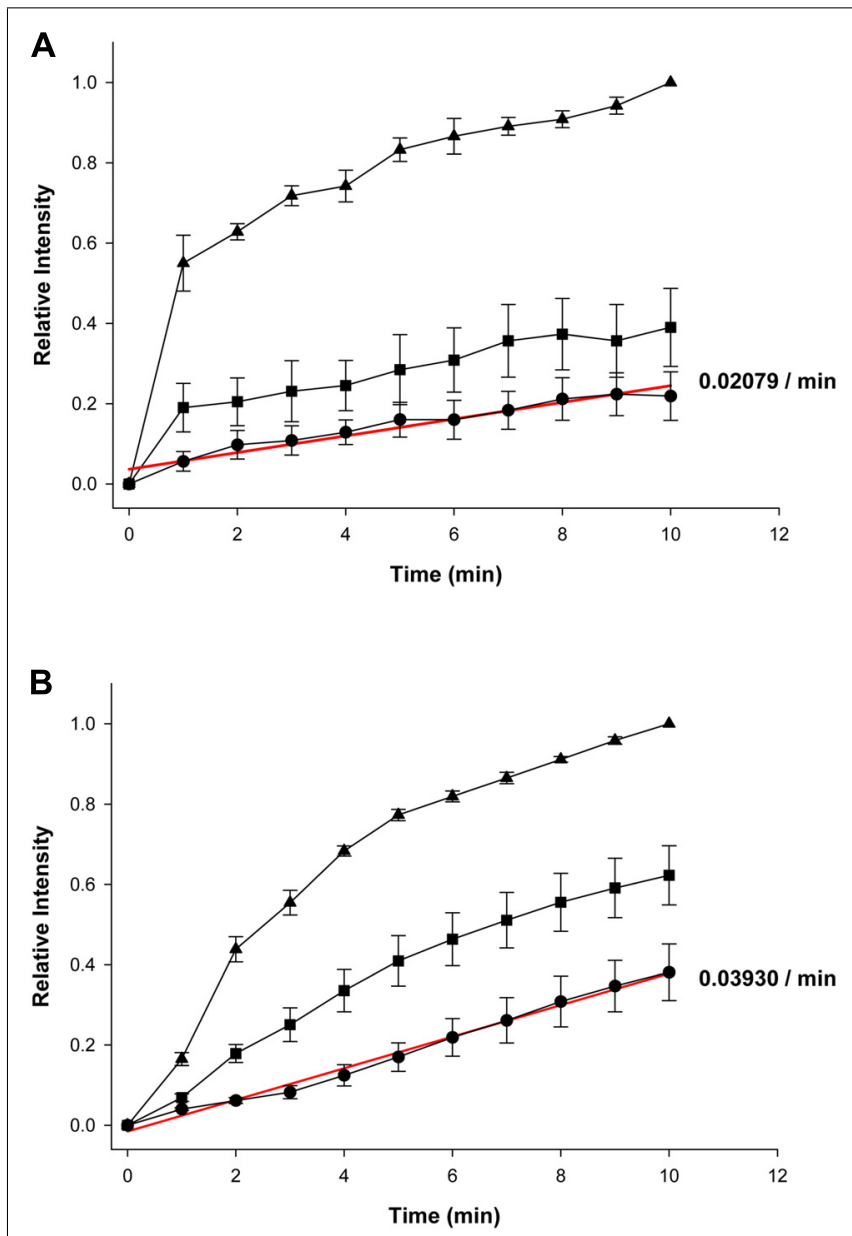

FIGURE 2 | Summary plots of fluorescence intensity versus time.

(A) Summary of averaged and normalized control ( $n=6$ experiments) and (B) $5 \mathrm{mM} 4$ 4-PB data ( $n=4$ experiments). First (source) cell ( $\mathbf{\Delta})$, second cell $(\boldsymbol{\square})$, and third cell $(\bullet)$. Error bars are representative of SE. Solid red lines correspond to the first-order regressions with $r^{2}=0.94$ and $r^{2}=0.99$ for control and 4-PB treated cells, respectively. 
cell. In control cells, the third cell was able to reach $\sim 21 \%$ of the concentration reached by the loading cell compared to the $\sim 39 \%$, which was achieved in the $5 \mathrm{mM} 4$-PB group (Figures 2A,B) in the same time period (10 $\mathrm{min})$.

Because dye transfer between each adjacent cell occurred through Cx43 comprised gap junction channels, comparing the increase in LY fluorescence intensity in the third cell correlates to the amount of $\mathrm{Cx} 43$ channels present between adjacent cells. Linear fits of the third cell data to first-order regression (red lines, Figures 2A,B) yielded the following slopes: $0.02079 \pm 0.001752 / \mathrm{min}$ and $0.03930 \pm 0.001233 / \mathrm{min}$ for control and 4-PB treated cells, respectively. Comparison of the regression lines by analysis of covariance (GraphPad Prism) revealed that the difference between the slopes was significant $(p<0.001)$.

These findings point to an increase of dye permeation upon exposure to 4-PB. Previous studies (Asklund et al., 2004; Khan et al., 2007) have also shown enhanced dye spread with exposure to $4-\mathrm{PB}$. This can be explained by an increase in the number of functioning channels resulting from increased expression. It is also possible that an increase in junctional conductance might arise from an increase of unitary channel conductance/permeability of Cx43 gap junction channels upon exposure to $5 \mathrm{mM} 4$-PB. In addition, changes in channel open probability would be predicted to affect junctional conductance. Does 4-PB affect any of these parameters?

\section{MACROSCOPIC AND UNITARY CONDUCTANCES of CX43 GAP JUNCTIONS}

An important experiment was to determine the effect of 4-PB on macroscopic gap junction conductance. Gap junction currents in HEK-293 cells were recorded using the double whole cell patch clamp. Figure $3 \mathbf{A}$ shows the voltage protocol $\left(V_{1}, V_{2}\right)$ and junctional currents recorded from control cells (left panel) and cells treated with $5 \mathrm{mM} 4$-PB (right panel). Starting from a holding voltage, $V_{h}$ of $0 \mathrm{mV}$, bipolar pulses of $400 \mathrm{~ms}$ were delivered to the one cell of a pair to establish $V_{\mathrm{j}}$ gradient of identical amplitude with either polarity from \pm 10 to $\pm 110 \mathrm{mV}$ in increments of $20 \mathrm{mV}$ (top panel, Figure 3A). In both groups junctional currents exhibited voltage dependent gating typical to $\mathrm{Cx} 43$ gap junction channels. The junctional conductances measured in control cells and cells treated with 4-PB are summarized in Figure 3B. The average junctional conductances in the control and $5 \mathrm{mM} 4$-PB groups were $16.9 \pm 1.8 \mathrm{nS}(n=32)$ and $22.7 \pm 1.7 \mathrm{nS}(n=31)$, respectively. These data indicate a statistically significant $(p=0.011)$ increase in gap junction conductance between these two groups of cells. Previous experiments have suggested that increases in Cx43 expression and number of $\mathrm{Cx} 43$ comprised gap junctions are reflected by enhanced gap junctional conductance in double cell patch clamp experiments (Dhein, 2004).

The effect of $4-\mathrm{PB}$ on unitary conductance of $\mathrm{Cx} 43$ gap junction channels was determined in selected pairs where only one or two operational channels were observable.

The pulse protocol involved an inversion of $V_{\mathrm{j}}$ polarity but of equal magnitude. Figure 4A shows single channel currents recorded from a 4 -PB $(5 \mathrm{mM})$ treated $\mathrm{HeLa} \mathrm{Cx} 43$ cell pair (middle panel) and control HeLa Cx43 cell pair (lower panel). The

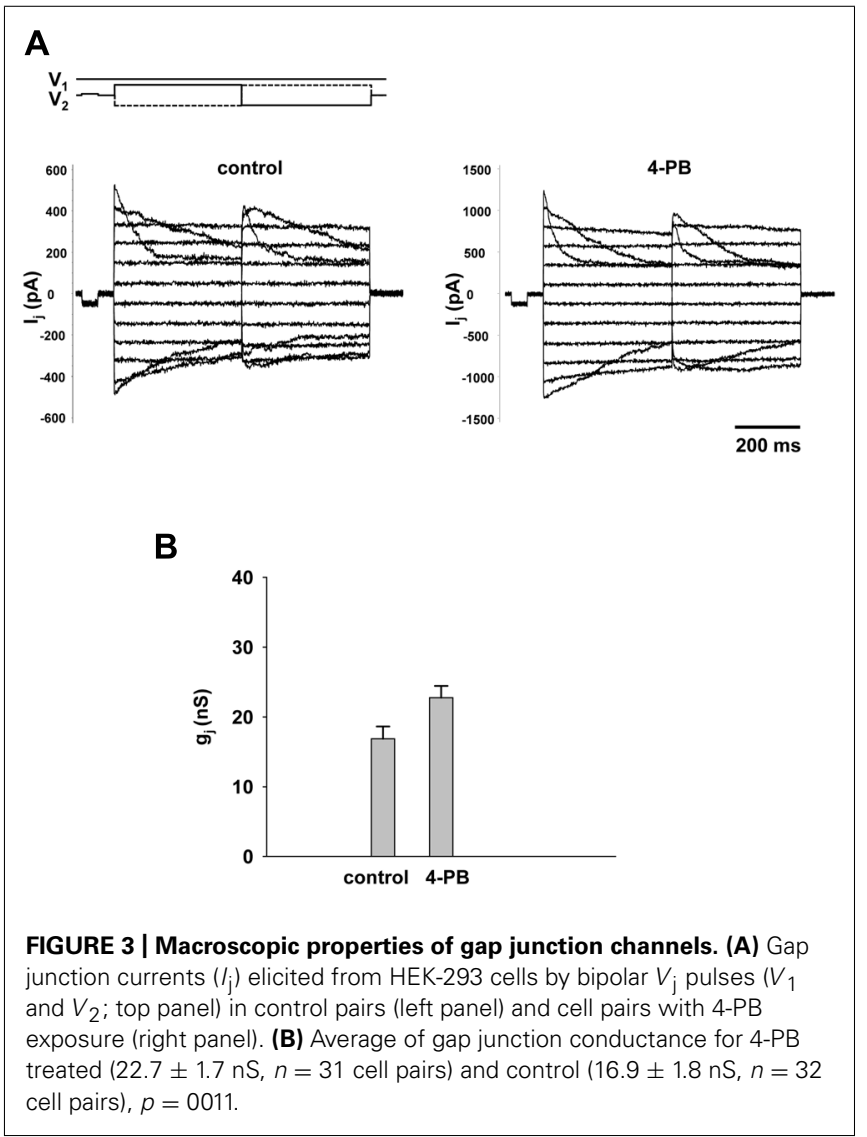

histograms in Figure 4B summarizes the data collected from five HeLa Cx43 cell pairs treated with $5 \mathrm{mM} 4$-PB (left panel) and four control HeLa Cx43 cell pairs. Both data groups were fitted with a Gaussian (solid lines). The 4-PB treated cells yielded a mean value of $51.7 \pm 3.1 \mathrm{pS}(n=66)$ and control cells revealed unitary conductance of $51.4 \pm 2.5 \mathrm{pS}(n=27), p=0.386$. The unitary conductance values correspond to the previously reported $\mathrm{Cx} 43$ unitary conductances in $120 \mathrm{mM} \mathrm{K}^{+}$aspartate $^{-}$solution (Valiunas et al., 2002). These data indicate that 4-PB does not affect the unitary conductance of $\mathrm{Cx} 43$ gap junction channels. The long duration open times are similar for the records shown and are consistent with the notion that 4-PB did not significantly affect open probability (Brink et al., 1996).

\section{WESTERN BLOT ANALYSIS}

The gap junction protein Cx43 was detected in cell cultures by Western blot analysis using a commercially available, polyclonal, anti-Cx43 antibody (C 6219, Sigma). 4-PB was exposed to cells in concentrations of: $0,1,2$, and $5 \mathrm{mM}$. The observed changes in the Cx43 expression are shown in Figure 5. The Western blots qualitatively demonstrate that the total Cx43 content in HEK-293 and HeLa Cx43 cells increases upon exposure of cells to $4-\mathrm{PB}$ as compared to cells not exposed to 4-PB. The quantification of the Western blots data shown in Figure 5A using ImageJ software yielded the following: the amount of $\mathrm{Cx} 43$ with $5 \mathrm{mM} 4$-PB exposure was $\sim 70 \%$ greater in HEK-293 cells and $\sim 40 \%$ greater in HeLa Cx43 cells in comparison to control cells. Anti- $\alpha$ tubulin 


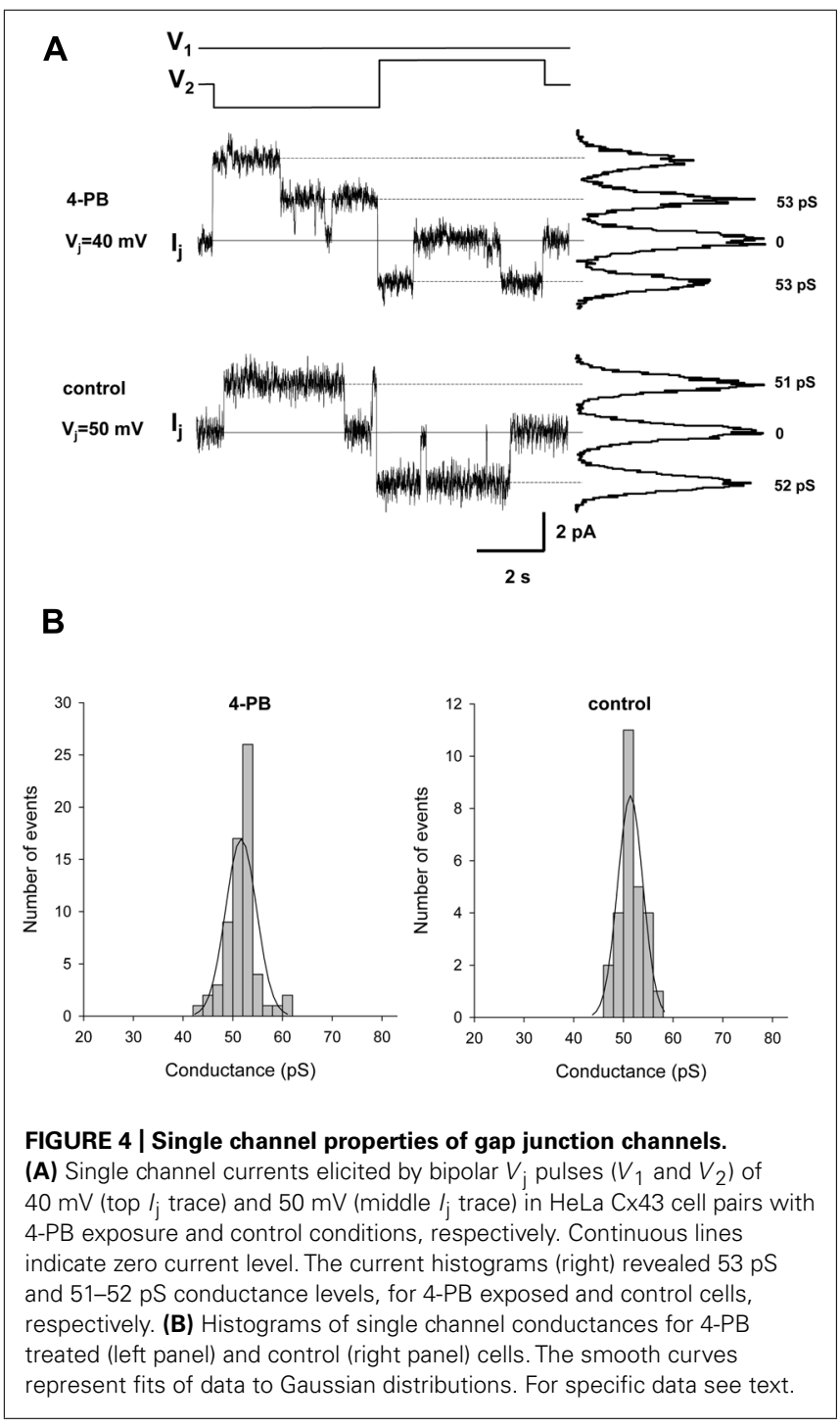

is shown, as a reference indicating that 4 - $\mathrm{PB}$ was the modulated variable in each of the dose experiments. Both cell types showed increased expression of Cx43 with 4-PB. The data with $5 \mathrm{mM} 4$-PB from four different experiments with HEK-293 cells are summarized in Figure 5B. The 4-PB treated cells exhibited statistical significant increase $(p=0.029)$ in the Cx43 expression in comparison to the control cells (166 \pm 11 versus $100 \%$, respectively).

These data are consistent with previously published studies showing 4-PB increase the expression of $\mathrm{Cx} 43$ and manifest in Western blot (Asklund et al., 2004; Khan et al., 2007; Dovzhanskiy et al., 2012).

\section{DISCUSSION}

\section{GAP JUNCTION COMMUNICATION}

The increased rate of LY dye transfer and junctional conductance seen in cells exposed to $5 \mathrm{mM} \mathrm{4-PB}$ for $24 \mathrm{~h}$ indicates that there are more $\mathrm{Cx} 43$ gap junction channels functioning as a consequence of increased connexin expression. The conclusion that

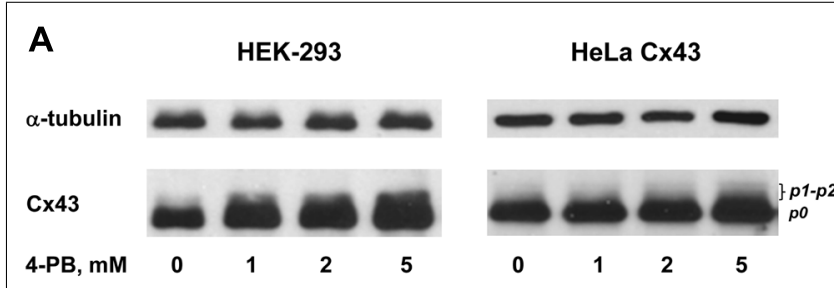

B

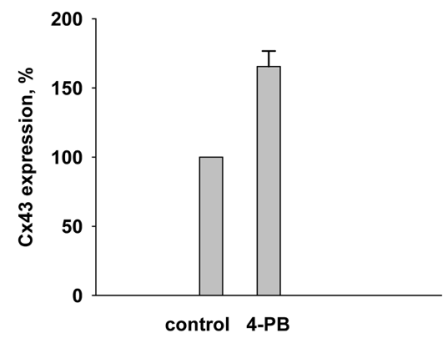

FIGURE 5 | (A) Western blot analysis of HEK-293 (left panel) and HeLa Cx43 (right panel) cells using polyclonal $\mathrm{C} \times 43$ antibody. Lines from left to right correspond to $0,1,2$, and $5 \mathrm{mM} 4-\mathrm{PB}$, respectively. Anti- $\alpha$ tubulin is shown as a reference indicator. (B) Summary of Western blot data from four experiments with HEK-293 control cells and cells exposed to $5 \mathrm{mM} 4$-PB. Upon exposure to $5 \mathrm{mM} 4$-PB Cx43 expression increased to $166 \pm 11 \%$ which was statistically significant $(p=0.029)$ in comparison to the control cells (0 mM 4-PB) where Cx43 expression was assumed to be $100 \%$.

4-PB increased expression and subsequently resulted in more functional channels is supported by the fact the single channel unitary conductance is unaffected by 4-PB along with no apparent change in open probability (Brink et al., 1996). Consistent with this conclusion is the increased expression of $\mathrm{Cx} 43$ as demonstrated by Western blot analysis (Asklund et al., 2004; Khan et al., 2007). The data support the notion that 4-PB enhances transcription of $\mathrm{Cx} 43$ mRNA, which ultimately results in an increase in the number of active channels.

However, the 4-PB induced $\mathrm{Cx} 43$ expression or protein abundance and functional coupling do not necessarily follow a one to one relationship. In fact previous studies have provided evidence that expression exceeds the number of functional channels (Asklund et al., 2004; Khan et al., 2007). Another confounding factor is the number of functioning channels within a junctional plaque. Bukauskas et al. (2000) demonstrated that only a small fraction $(\sim 10 \%)$ of channels function at any instant in time with a given plaque.

Histone deacetylase inhibitors are potent regulators of gene expression through their effect on the acetylation of core histones (Asklund et al., 2004). Comparison of Figures 2A,B indicates that cells exposed to $5 \mathrm{mM} 4$-PB allowed for greater dye transfer across the three cell liner arrays so that the cell furthest away from the source cell was able to obtain a much greater level of LY dye over a 10-min time interval. There was a marked difference in dye distribution among the three adjacent cells when comparing the 
control and $5 \mathrm{mM} 4$-PB groups. In the control cells, less dye was able to diffuse into the second and third cells. This is opposed to the cells exposed to $5 \mathrm{mM} 4-\mathrm{PB}$, which exhibited a much more even distribution of dye across all three of the adjacent cells. This is consistent with a 4-PB induced increase in gap junctions resulting in a more effective diffusive pathway. In other words an increased number of $\mathrm{Cx} 43$ gap junction channels allows for better dye transfer between each of the cells. In the control cells, fewer $\mathrm{Cx} 43$ gap junction channels caused the dye to pool mostly in the first cell with a decreased transfer between cells. Hence, 4-PB was able to enhance functional intercellular communication. This finding has several implications, as LY can be substituted for any number of different drugs or second messenger molecules.

\section{CONNEXINS AND CARDIAC DYSFUNCTION}

Currently, VT and ventricular fibrillation (VF) are two of the leading causes of death in the United States (Xing et al., 2003). Previous studies have provided evidence that abnormal functioning of gap junctions in cardiac tissue may play an important role in the induction of both VF and VT (Xing et al., 2003). In the heart, normal cardiac function relies on the electrical syncytium between adjacent cells in the myocardium. The spread of an electrical impulse is highly coordinated and any blockage that disrupts cell-to-cell communication has immediate and harmful consequences (Xing et al., 2003). A period of acute ischemia causes gap junction channels to close, leading to an uncoupling of all adjacent cells. Similarly, a prolonged period of ischemia is correlated to a non-uniform down regulation of $\mathrm{Cx} 43$ (Xing et al., 2003). The closure of gap junction channels combined with a decrease in $\mathrm{Cx} 43$ translation leaves the heart particularly susceptible to reentrant ventricular

\section{REFERENCES}

Asklund, T., Appelskog, I., Appelskog, I. B., Ammerpohl, O., Ekstrom, T. J., and Almqvist, P. M. (2004). Histone deacetylase inhibitor 4phenylbutyrate modulates glial fibrillary acidic protein and connexin 43 expression and enhances gap junction communication, in human glioblastoma cells. Eur. J. Cancer 40, 1073-1081. doi: 10.1016/j.ejca. 2003.11.034

Brink, P., Ramanan, S., and Christ, G. (1996). Human connexin 43 gap junction channel gating: evidence for mode shifts and/or heterogenicity. Am. J. Physiol. 271, 321-331.

Bukauskas, F. F., Jordan, K., Bukauskiene, A., Bennett, M. V. L., Lampe, P. D., Laird, D. W., et al. (2000). Clustering of connexin 43enhanced green fluorescent protein gap junction channels and functional coupling in living cells. Proc. Natl. Acad. Sci. U.S.A. 97, 2556-2561. doi: 10.1073/pnas.050588497

Dhein, S. (2004). Pharmacology of gap junctions in the cardiovascular system. Cardiovasc. Res. 62,
287-298. doi: 10.1016/j.cardiores. 2004.01.019

Dhein, S., Larsen, B. D., Petersen, J. S., and Mohr, F. W. (2003). Effects of the new antiarrhythmic peptide ZP123 on epicardial activation and repolarization pattern. Cell Commun. Adhes. 10, 371-378. doi: 10.1080/cac.10.46.371 .378

Donahue, J. K., and Laurita, K. R. (2011). "Trachyarrhythmia therapies: approaches to atrial fibrillation and postinfarction ventricular arrhythmias," in Regenerating the Heart: Stem Cells and the Cardiovascular System, eds I. S. Cohen and G. Gaudette (New York, NY: Springer), 349-378.

Dovzhanskiy, D. I., Hartwig, W., Lazar, N. G., Schmidt, A., Felix, K., Straub, B. K., et al. (2012). Growth inhibition of pancreatic cancer by experimental treatment with 4-phenylbutyrate is associated with increased expression of connexin43. Oncol. Res. 20, 103-111. doi: $10.3727 / 096504012 X 134771451$ 52959

Gemel, J., Valiunas, V., Brink, P., and Beyer, E. (2004). Connexin 43

circuits and subsequently, VT or VF. The disruption of impulse propagation through the ventricular myocardium causes an irregular contraction of the ventricles. Instead of the action potential traveling normally throughout the ventricle, a decrease in gap junctions causes the electrical signal to propagate more slowly allowing for reentrant arrhythmias. This causes sporadic contraction of different parts of the ventricle known as VF. The incidence of VF has been directly related to decreased connexin levels (Xing et al., 2003). Because the drug 4-PB can induce connexin mRNA transcription, it is possible that the drug could effectively trigger renewed channel formation reduced by cardiac ischemia. Thus, the findings in this study suggest that drugs such as 4-PB which enhance gap junction coupling, might be implicated in the prevention of ischemia induced VT or VF as earlier has been shown with the anti-arrhythmic peptide ZP123 (Xing et al., 2003). In addition, another related study has shown that 4-PB significantly enhanced coupling and action potential propagation between rodent cardiomyocytes (Jia et al., 2012) suggesting that cardiac cells may be responsive to HDAC inhibitors and, hence potentially useful as a cardiac therapy.

However, it remains to be seen whether drugs like 4-PB will be effective in preventing ischemia induced cardiac maladies. Yet more thorough studies have to be done in arrhythmia models to test 4-PB potential to act as anti-arrhythmic gap junction modulator similar to anti-arrhythmic peptides AAP10 and ZP123 (Dhein et al., 2003).

\section{ACKNOWLEDGMENTS}

This work was supported by NIH grants GM RO1 088180 to Peter R. Brink and GM RO1 088181 to Virginijus Valiunas and HL 094410 to Ira S. Cohen.

and connexin26 for gap junctions, but not heteromeric channels in co-expressing cells. J. Cell Sci. 117, 2469-2480. doi: 10.1242/jcs. 01084

Hodgkin, A. L., and Huxley, A. F. (1952). A quantitative description of membrane current and its application to conduction and excitation in nerve. J. Physiol. 117, 500-544.

Jia, Z., Bien, H., Shiferaw, Y., and Entcheva, E. (2012). Cardiac cellular coupling and the spread of early instabilities in intracellular $\mathrm{Ca}^{2+}$. Biophys. J. 102 , 1294-1302. doi: 10.1016/j.bpj.2012. 02.034

Khan, Z., Akhtar, M., Asklund, T. Juliusson, B., Almqvist, P., and Ekstrom, T. (2007). HDAC inhibition amplifies gap junction communication in neural progenitors: potential for cell mediated enzyme prodrug therapy. Exp. Cell Res. 313, 29582967. doi: 10.1016/j.yexcr.2007. 05.004

Pointis, G. (2006). Connexin43: emerging role in erectile function. Int. J. Biochem. Cell Biol. 38, 1642-1646. doi: 10.1016/j.biocel.2006.03.007
Rudy, Y. (2001). The ionic mechanisms of conduction in cardiac tissue. J. Electrocardiol. 34, 65-68. doi: 10.1054/jelc.2001. 28831

Saffitz, J. E., Hames, K. Y., and Kanno, S. (2007). Remodeling of gap junctions in ischemic and nonischemic forms of heart disease. J. Membr. Biol. 218, 65-71. doi: 10.1007/s00232-0079031-2

Sohl, G., and Willecke, K. (2004). Gap junctions and the connexin protein family. Cardiovasc. Res. 62, 228232. doi: 10.1016/j.cardiores.2003. 11.013

Valiunas, V., Beyer, E., and Brink, P. (2002). Cardiac gap junction channels show quantitative differences in selectivity. Circ. Res. 91, 104-111. doi: 10.1161/01.RES.0000025638. 24255.AA

Valiunas, V., Gemel, J., Brink, P., and Beyer, E. (2001). Gap junction channels formed by coexpressed connexin40 and connexin43. Am. J. Physiol. Heart Circ. Physiol. 281, 1675-1689.

Valiunas, V., Mui, R., McLachlan, E., Valdimarsson, G., Brink, P., 
and White, T. (2004). Biophysical characterization of zebra fish connexin35 hemichannels. Am. J. Physiol. Cell Physiol. 287, 15961604. doi: 10.1152/ajpcell.00225. 2004

Valiunas, V., Weingart, R., and Brink, P. (2000). Formation of heterotypic gap junction channels by connexins 40 and 43. Circ. Res. 86, 42-49. doi: 10.1161/01.RES.86. 2.e42

Xing, D., Kjolbye, A., Nielsen, M., Petersen, J., Harlow, K., Rathlou, N., etal. (2003). ZP123 increases gap junctional conductance and prevents reentrant ventricular tachycardia during myocardial ischemia in open chest dogs. J. Cardiovasc. Electrophysiol. 14, 510520. doi: 10.1046/j.1540-8167.2003. 02329.x

Conflict of Interest Statement: The authors declare that the research was conducted in the absence of any commercial or financial relationships that could be construed as a potential conflict of interest.
Received: 13 February 2013; accepted: 14 August 2013; published online: 03 September 2013.

Citation: Kaufman J, Gordon C, Bergamaschi R, Wang HZ, Cohen IS, Valiunas $V$ and Brink PR (2013) The effects of the histone deacetylase inhibitor 4-phenylbutyrate on gap junction conductance and permeability. Front. Phar macol. 4:111. doi: 10.3389/fphar.2013. 00111

This article was submitted to Pharmacology of Ion Channels and Channelopathies, a section of the journal Frontiers in Pharmacology.
Copyright (c) 2013 Kaufman, Gordon, Bergamaschi, Wang, Cohen, Valiunas and Brink. This is an openaccess article distributed under the terms of the Creative Commons Attribution License (CC BY). The use, distribution or reproduction in other forums is permitted, provided the original author(s) or licensor are credited and that the original publication in this journal is cited, in accordance with accepted academic practice. No use, distribution or reproduction is permitted which does not comply with these terms. 